Jurnal Keuangan dan Perbankan, Vol.20, No.2 Mei 2016, hlm. 314-321

Terakreditasi SK. No. 040/P/2014

http://jurkubank.wordpress.com

\title{
DAMPAK TERUKUR FASILITAS KREDIT USAHA MIKRO POLA TANGGUNGRENTENG SEBAGAI ALAT PEMBETUK LENDING MODEL BAGI USAHA MIKRO PEMULA DAN PROGRAM PENDANAAN BERKELANJUTAN
}

\author{
Sunardi \\ Lita Dwipasari \\ Fakultas Ekonomi dan Bisnis Program Studi D III Keuangan \& Perbankan \\ Universitas Merdeka Malang
}

\begin{abstract}
The objectives of this research are to examine the revenue impact and the repayment capacity of working modal credit facility for Small Medium Eterprises by using joint liability. This research used a correlational ap-proach and purposive sampling technique with several criteria such as: (1) Small Medium Eterprises should have 5 (five) people minimally; (2) Small Medium Eterprises have been guided by a university; (3) Small Medium Eterprises have got a loan from a bank. The result of this research shows that the revenue and the rep6ayment capacity from the fourth Small Medium Eterprises have increased. The highest revenue is ob-tained from Batik sector and the lowest revenue is obtained from convection sector.
\end{abstract}

Keywords: income, repayment capacity, business group

Di seluruh dunia, usaha mikro, kecil dan menengah (UMKM) menjadi mesin pertumbuhan ekonomi serta alat pemerataan pembangunan (Harash et al 2013;. Harash et al 2014.). Usaha mikro, kecil dan menengah (UMKM) merupakan alat yang tangguh untuk mengurangi kemiskinan. Salah satu cara untuk mengurangi kemiskinan di Negara berkembang termasuk di Indonesia se-cara berkelanjutan adalah dengan meningkatkan pertumbuhan ekonomi, melalui penciptaan lapangan kerja di sektor Usaha mikro (Kraja \& Osmani, 2013). usaha kecil dan menengah (UKM) memainkan peran berharga dalam penciptaan lapangan kerja dan memberikan kontribusi signifikan terhadap pertumbuhan ekonomi di maju dan negara berkembang sama. Akibatnya, membangun usaha mikro, kecil yang dinamis merupakan prioritas pembangunan ekonomi hampir semua negara di seluruh dunia (Tambunan, 2005). Untuk mencapai pertumbuhan ekonomi yang berkelanjutan melalui usaha mikro, diperlukan adanya hubungan yang saling menguntungkan antara usaha mikro, kecil dengan sektor lembaga keuangan agar pemberian fasilitas kredit oleh lembaga keuangan berdampak terhadap

Korespondensi dengan Penulis:

Sunardi: Telp +62 8125218443

Email: nardisu92@yahoo.com 


\section{Dampak Terukur Fasilitas Kredit Usaha Mikro Pola Tanggungrenteng...}

Sunardi \& Lita Dwipasari

pertumbuhan usaha mikro, kecil. Penelitian empi-ris dampak terukur kredit bagi usaha mikro masih belum konsisten. Keputusan tanbahan modal dari yang diperoleh pinjaman terhadap perubahan laba perusahaan ditemuai pada penelitian Rachmawati \& Hotniar (2007), Dewi \& Syahrir (2013). Tetapi penelitian yang dilkukan oleh Olowe F.T (2013) menemukan, jangka waktu pinjaman berdampak tidak signifikan terhadap pertumbuhan usaha. Penelitian mengenai dampak kredit perbankan terhadap pertumbuhan usaha perusahaan telah banyak dilakukan. Namun, penelitian tentang dampak terukur kredit pola tanggungrenteng terhadap pertumbuhan usaha mikro masih relatif sedikit. Kinerja perusahaan diukur dengan perbedaan indicator keuntungan, pertumbuhan penjualan, peningkatan persediaaan dan peningkatan nilai aktiva tetap, Meyanathan and Munter (1994).

\section{Pengukuran Akses kredit dan Kinerja Keuangan}

\section{Pengukuran Akses Kredit}

Walaupun akses kredit tidak mudah untuk diukur, financial dept(totl loan outstanding) dapat di lihat dari indicator dampak secara lansung dan tidak langsung pada keuangan perusahaan. Hutang yang besar dapat diasumsikan pada akses kredit yang tinggi. Demirguc-Kunt, Beck and Martinez (2007) mengidentifikasikan ukuran perusahaan, jumlah simpanan sebagai indicator dari jumlah pinjaman di bank. Suku bunga kredit merupakan bagian dari biaya kredit. Bunga kredit biasanya diperhitungkan dari jumlah pinjaman, waktu pinjaman. Tingginya bunga kredit yang di bebankan kepada usaha mikro dikarenakan bank masih melihat tinggginya resiko yang dimiliki oleh sektor usaha mikro. Pertama, Akses kredit bagi usaha mikro masih terkedala pada masalah agunan, kondisi ini merupakan hambatan bagi usaha mikro untuk akses pinjman ke lembaga perbankan. Kedua, insitusi dapat menjadi jaminan bagi peninjam usaha mikro secara individu maupun kelompok, karena bank peraturan perbankan tidak memperkenankan pinjaman tanpa jaminan.

\section{Pengukuran Kinerja Keuangan/perusahaan}

Pengukuran kinerja pada Usaha Mikro, kecil menurut (Anderson \& Reeb, 2003; Ittner \& Larcker, 2003; Juhl et al. 2002; Petersen \& Schoeman, 2008; Sabanci Ozer, 2012; Sacristan-Navarro et al. 2011; Selvarajan et al. 2007; Thri-kawala, 2011; Watson, 2007) mendifinisikan se-berapa besar kegiatan perusahaan untuk menggu-nakan asset yang dimiliki guna memperoleh pendapatan. Dalam pengukuran kinerja keuangan, di intepretasikan sejumlah analisa laporan ke-uangan dan pendapat pribadi dapat di jadikan alat ukur dalam mengitepretasikan kinerja keuangan. Pendapat lain dikemukakan oleh Kaplan ad Norton (1992), dimana pengukuran kinerja keuangan menggunakan harga pasar untuk mengevaluasi kinerja keuangan, sebab harga pasar merupakan factor eksternal yang tidak bisa dikontrol oleh pengelola perusahaan. Dimana harga pasar adalah harga yang aman yang dapat digunkan untuk mengukur kinerja keuangan dan pasar tidak dapat di gunkaan pada data akuntasi dalam mengukur kinerja keuangan. Adapun teknik analisis yang digunakan untuk mengukur kinerja keuangan dengan menggunakan analisa rasio, analisa trent dan cross sectional analysis Padley (1997). Adapun pengukuran kinerja keuangan dapat diklasifika-sikan, rasio likuiditas yang digunakan untuk meng-ukur kemampuan perusahan dalam melunasi kewajiban jangka pendek, rasio solvabilitas untuk mengukur kemampuan perusahaan dalam melunasi semua kewajibannya, rasio efisiensi untuk meng-ukur efektifitas pengelolaan asset dan profitabilitas yang digunakan untuk mengukur kemampuan perusahaan dalam menghasilkan laba dari investasi yang di tanam. Gardner, Mills ad Cooperman (2005), menyatakan bahwa ROI merupakan ukuran yang digunakan untuk mengevaluasi terhadap efisiensi dari pengelolaan asset untuk mengahasil- 
kan laba, ROE digunakan untuk mengukur mengukur tingkat pendapatan dari investasi yang ditanam oleh investor.

\section{METODE}

Populasi dalam penelitian ini adalah kelompok usaha mikro binaan Perguruan Tinggi di Kota Malang yang tergabung dalam kelompok Posdaya. Data merupakan data primer yang diper-oleh dari usaha mikro kelomp-ok posdaya. Teknik pengambilan sampel dengan menggunakan purpo-sive sampling dengan beberapa kriteria sebagai be-rikut: (1) Kelompok usaha mikro memiliki ke-lompok minimal 5 (lima) orang (2) Usaha mikro telah menjadi binaan perguruan tinggi. (3) Usaha mikro telah mendapatkan pinjaman dari Per-bankan.

Berdasarkan tiga kriteria di atas maka diperoleh 12 kelompok usaha mikro yang tealah medapatkan pinjaman secara tanggungrenteng selama periode 2014. Sedangkan berdasarkan kreteria jenis usaha mikro yang akan diobservasi diperoleh empat kelompok usaha, kelompok usaha konveksi,makanan minuman, peternakan dan kelompok batik.

\section{Hasil dan Pembahasan}

Hasil Setelah dilakukan perhitungan analisis kredit dengan model pendekatan kualitatif dan kuantitaif, diperoleh hasil dampak pinjaman keuangan model tanggungrenteng terhadap per-ubahan Repayment Capacity, seperti tertera dalam Tabel 1:

Dari Tabel 1 diatas, besarnya omzet penjualan sebelum mendapatkan pinjaman Rp. 37.500.000; laba kotor Rp 8.800.000, pengeluaran Rp 4.800.000; serta laba bersih sebesar Rp 4.000.000; dan sesudah mendapatkan pinjaman diperkirakan terdapat kenaikan omzet penjualan sebesar $40 \%$, berdam-pak pada kenaikan penjualan sebesar Rp 7.800.000, Laba Kotor Rp 12.600.000 dan pengeluaran $\operatorname{Rp} 4.800 .000$, sehingga laba menjadi Rp 7.800.000. Dari kenyataan Repayment Capacity: 90 \% x (a) Rp 7.800 .000 atau sebesar Rp 7.020.000; dapat dikata-

Tabel 1: Dampak Terukur Lending Model Kelompok Usaha Konveksi

\begin{tabular}{|c|c|c|c|c|c|}
\hline \multicolumn{3}{|l|}{ Sebelum Mendapat Pinjaman } & \multicolumn{3}{|c|}{ Sesudah Mendapat Pinjaman } \\
\hline \multicolumn{3}{|l|}{ Penerimaan } & \multicolumn{3}{|c|}{ Penerimaan: } \\
\hline - Omzet penjualan & $\mathrm{Rp}$ & 37.500 .000 & - Omzet penjualan & $\mathrm{Rp}$ & 52.500 .000 \\
\hline - Harga Pokok Pembelian & $\mathrm{Rp}$ & 28.700 .000 & HPP & $\mathrm{Rp}$ & 39.900 .000 \\
\hline - Laba Kotor & $\mathrm{Rp}$ & 8.800 .000 & Laba Kotor & $\mathrm{Rp}$ & 12.600 .000 \\
\hline \multicolumn{3}{|l|}{ Pengeluaran: } & \multicolumn{3}{|l|}{ Pengeluaran: } \\
\hline - Upah Tenaga Kerja & $\mathrm{Rp}$ & 2.500 .000 & -Upah Tenaga Kerja & $\mathrm{Rp}$ & 2.500 .000 \\
\hline - Listrik, Telp, Air & $\mathrm{Rp}$ & 400.000 & -Listrik, Telp, Air & $\mathrm{Rp}$ & 400.000 \\
\hline - Pajak / Retribusi & $\mathrm{Rp}$ & 200.000 & -Pajak / Retribusi & $\mathrm{Rp}$ & 200.000 \\
\hline - Bi Rumah Tangga & $\mathrm{Rp}$ & 1.500 .000 & -Baya Rumah Tanggal & $\mathrm{Rp}$ & 1.500 .000 \\
\hline -Lain-lain & $\mathrm{Rp}$ & 200.000 & -Lain - lain & $\mathrm{Rp}$ & 200.000 \\
\hline Jumlah pengeluaran & $\mathrm{Rp}$ & 4.800 .000 & Jumlah pengeluaran & $\underline{\mathrm{Rp}}$ & 4.800 .000 \\
\hline Pendapatan neto & $\mathrm{Rp}$ & 4.000 .000 & Pendapatan (neto) & $\overline{R p}$ & 7.800 .000 \\
\hline \multicolumn{3}{|c|}{ Pendapatan sampingan neto(Istri) } & \multicolumn{3}{|c|}{ Pendapatan sampingan (neto) } \\
\hline Jumlah Rugi / Laba & $\mathrm{Rp}$ & 4.000 .000 & Jumlah Rugi / Laba (a) & $\underline{R p}$ & 7.800 .000 \\
\hline \multicolumn{3}{|c|}{$\begin{array}{l}\text { Repayment Capacity: } 90 \% \text { X Rp 4. } 000.000=\text { Rp } \\
\text { 3.600.000; }\end{array}$} & \multicolumn{3}{|c|}{$\begin{array}{l}\text { Repayment Capacity: } 90 \% \text { X Rp } 7.800 .000= \\
\text { Rp 7.020.000; }\end{array}$} \\
\hline
\end{tabular}


kan bahwa model pembiayaan (lending model) dengan pola tanggung renteng memberi dampak terhadap kenaikan penjualan dan laba usaha. Dengan demikian, pembiayaan dengan (lending model) dengan pola tanggung renteng ini, dapat membantu usaha mikro yang belum bankable menjadi bankable, sehingga model ini juga dapat membantu dapat untuk mengurangi ketergantungan usaha mikro terhadap pelepas uang (rentenir).

Tabel 2: Dampak Terukur Lending Model Makanan Minuman

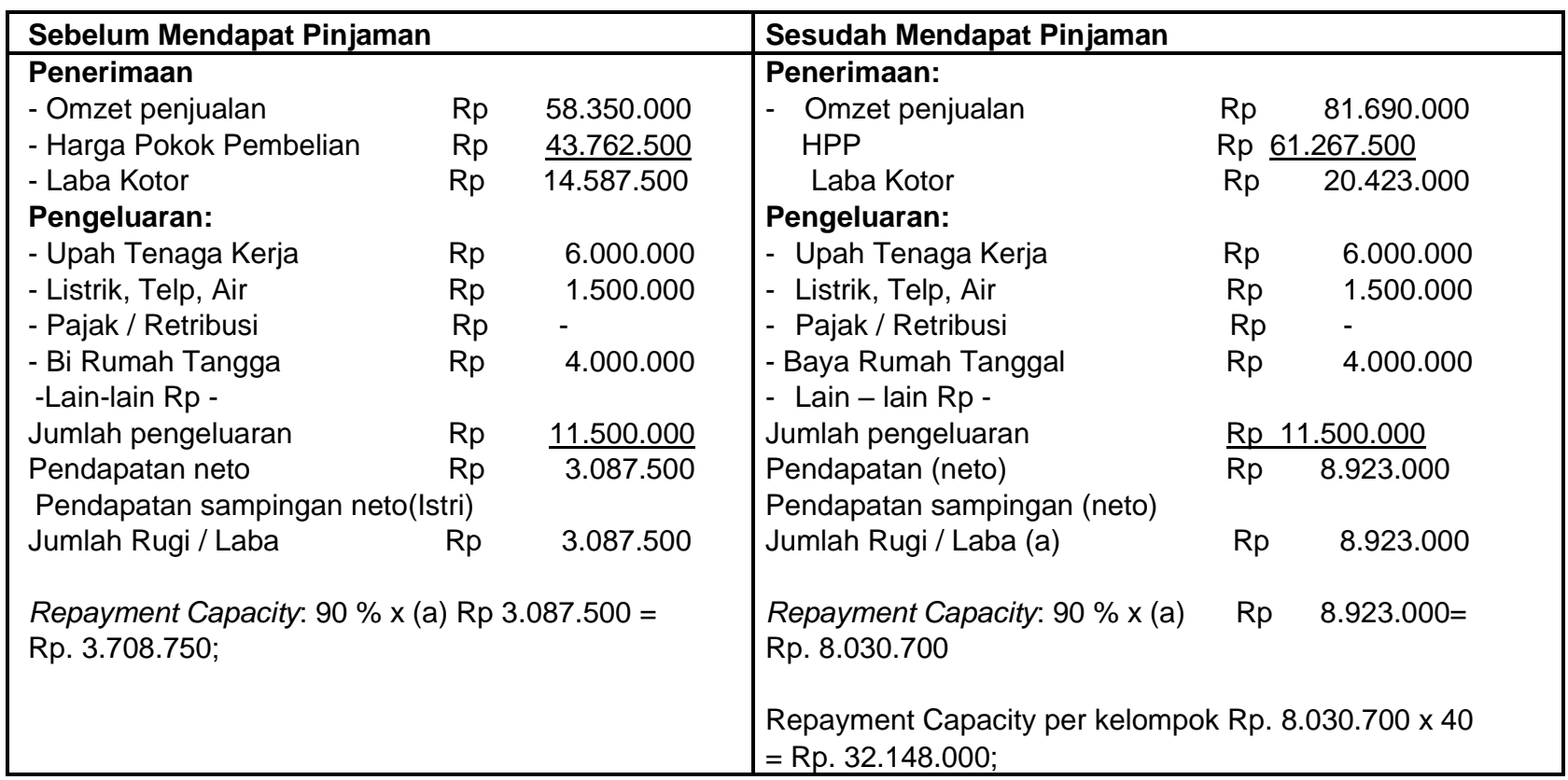

Tabel 3: Dampak Terukur Lending Model Kelompok Peternakan

\begin{tabular}{|c|c|c|c|c|c|}
\hline \multicolumn{3}{|c|}{ Sebelum Mendapat Pinjaman } & \multicolumn{3}{|l|}{ Sesudah Mendapat Pinjaman } \\
\hline \multicolumn{3}{|c|}{ Penerimaan } & \multicolumn{3}{|l|}{ Penerimaan: } \\
\hline - Omzet penjualan & Rp. & 60.000 .000 & - Omzet penjualan (naik 75 \%) & Rp. & 05.000 .000 \\
\hline - Harga Pokok Produksi & Rp. & $\underline{36.000 .000}$ & HPP & Rp. & $\underline{000.000}$ \\
\hline $\begin{array}{l}\text { - Laba Kotor } \\
\text { Pengeluaran: }\end{array}$ & Rp. & $\overline{24.000 .000}$ & $\begin{array}{l}\text { Laba Kotor } \\
\text { Pengeluaran: }\end{array}$ & Rp. & 42.000 .000 \\
\hline - Listrik, Telp, Air & Rp. & 1.500 .000 & - Listrik, Telp, Air & Rp. & 1.500 .000 \\
\hline - Pajak / Retribusi & Rp. & - & - Pajak / Retribusi & Rp. & - \\
\hline - Bi Rumah Tangga & Rp. & 4.000 .000 & - Baya Rumah Tanggal & Rp. & 4.000 .000 \\
\hline -Lain-lain & Rp. & 1.000 .000 & - Lain - lain & Rp. & 1.000 .000 \\
\hline Jumlah pengeluaran & Rp. & $\underline{6.500 .000}$ & Jumlah pengeluaran & $\underline{\mathrm{Rp}}$. & $\underline{6.500 .000}$ \\
\hline Pendapatan neto & Rp. & $17 \overline{7.500 .000}$ & Pendapatan (neto) & $\overline{\mathrm{Rp}}$. & $3 \overline{5.500 .000}$ \\
\hline Pendapatan sampingan $r$ & o(Istr & & Pendapatan sampingan (neto) & & \\
\hline Jumlah Rugi / Laba & Rp. & 17.500 .000 & Jumlah Rugi / Laba (a) & Rp. & 35.500 .000 \\
\hline \multicolumn{3}{|c|}{$\begin{array}{l}\text { Repayment Capacity: } 60 \% \text { x (a) Rp } 17.500 .000= \\
\text { Rp. } 10.500 .000 ; / 3 \text { bulan }\end{array}$} & \multicolumn{3}{|c|}{$\begin{array}{l}\text { Repayment Capacity: } 60 \% \text { x (a) Rp } 35.500 .000=\text { Rp. } \\
21.300 .000 ; / 3 \text { bulan }\end{array}$} \\
\hline & & & \multicolumn{3}{|c|}{$\begin{array}{l}\text { Repayment Capacityper kelompok Rp. } 21.300 .000 ; / 3 \\
\text { bulan x } 10=\text { Rp. } 213.000 .000\end{array}$} \\
\hline
\end{tabular}


Dari tabel 2 diatas, besarnya omzet penjualan sebelum mendapatkan pinjaman Rp. 58.350 .000 laba kotor Rp. 14.587.500, pengeluaran Rp. 11.500 .000 serta laba bersih sebesar Rp 3.087 .500 ; dan sesudah mendapatkan pinjaman diperkirakan terdapat kenaikan omzet penjualan sebesar $40 \%$, berdampak pada kenaikan penjualan sebesar Rp 81.690.000, Laba Kotor Rp 20.423.000 dan penge-luaran Rp11.500.000, sehingga laba menjadi Rp 8.923.000. Dari kenyataan Repayment Capacity 8.030.700:, dapat dikatakan bahwa model pem-biayaan (lending model) dengan pola tanggung renteng memberi dampak terhadap kenaikan penjualan dan laba usaha.

Dari tabel 25 diatas, besarnya omzet penjualan sebelum mendapatkan pinjaman Rp. 60.000 .000 laba kotor Rp. 24.000.000, pengeluaran Rp 6.500 .000 serta laba bersih sebesar 17.500 .000 ; dan sesudah mendapatkan pinjaman diperkirakan terdapat kenaikan omzet penjualan sebesar $75 \%$, berdampak pada kenaikan pendapatan sebesar Rp 105.000.000,
Laba Kotor Rp 35.500.000; dan pengeluaran $\mathrm{Rp}$ 6.500.000, sehingga laba menjadi Rp. 35.500 .000 Dari kenyataan Repayment Capacity:Rp.21.300.000 ; 3 bulan atau Rp.7.100.000; dapat dikatakan bahwa model pembiayaan (lending model) dengan pola tanggung renteng memberi dampak terhadap kenaikan penjualan dan laba usaha.

Dari tabel 3 diatas, besarnya omzet penjualan sebelum mendapatkan pinjaman Rp. 60.000 .000 laba kotor Rp. 24.000.000, pengeluaran Rp 6.500.000 serta laba bersih sebesar 17.500 .000 ; dan sesudah mendapatkan pinjaman diperkirakan terdapat kenaikan omzet penjualan sebesar $20 \%$, berdampak pada kenaikan pendapatan sebesar Rp, Laba Kotor Rp 13.500.000; dan pengeluaran Rp 6.500.000, sehingga laba menjadi Rp7.000.000. Dari kenyataan Repayment Capacity setelah mendapatkan tambahan modal menjadi Rp.5.600.000; dapat dikatakan bahwa model pembiayaan (lending model) dengan pola tanggung renteng memberi dampak terhadap kenaikan penjualan dan laba usaha.

Tabel 3: Dampak Terukur Lending Model Kelompok usaha Batik Malangan

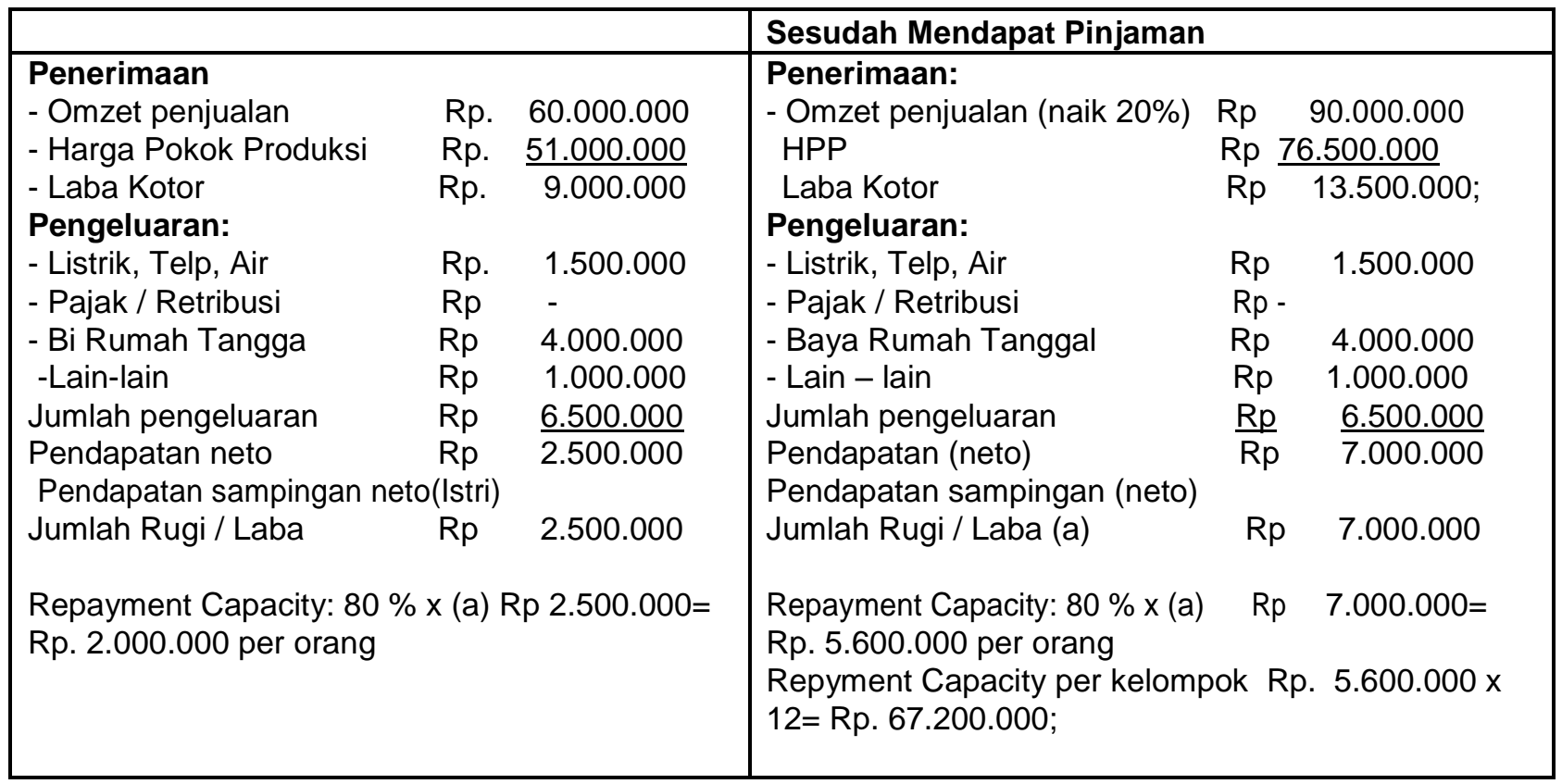




\section{Pembahasan}

Berdasarkan hasil analisis dampak terukur fasilitasi pinjaman kepada kelompok usaha mikro model tanggungrenteng, menunjukkan hasil yang signifikan sebagaimana ditunjukkan dalam Tabel 5. Dengan demikian, cukup bukti secara empiris bahwa keputusan Fasilitasi kredit kepada usaha mikro pemula dengan model tanggungrenteng berdampak terhadap secara langsung terhadap laba perusahaan. Temuan ini menunjukkan bahwa keputusan ini, membandingkan laba sebelum dan sesudah fasilitasi kredit yang diukur dengan kemampuan bayar(repayment capacity) mampu menjelaskan penambahan kemampuan bayar bagi kelompok usaha mikro pemula.

Temuan penelitian ini,mendukung hasil penelitian yang dilakukan oleh Henny ( ), Rachmawati \& Hotniar (2007), Dewi \& Syahrir (2013), dan Desna ( ), yang mana tambahan modal berdampak secara signifikan terhadap laba perusahaan. Tetapi hasil penelitian ini, tidak sejalan dengan hasil penelitian yang dilkukan oleh Olowe F.T (2013) menemukan, jangka waktu pinjaman berdampak tidak signifikan terhadap pertumbuhan usaha.

Dari tabel 5 diatas, dapat memberikan gambaran bahwa dengan adanya fasilitas kredit dari lembaga keuangan dapat berpengaruh terhadap perkembangan usaha mikro. Laba bersih yang diperoleh setelah mendapatkan kredit terdapat peningkatkan pada semua sektor usaha, kenaikan laba adlah sebagai berlkut: makanan minuman
$65 \%$, peternakan $50,7 \%$, konveksi $48,7 \%$,batik malangan $46,4 \%$. Sektor usaha makanan minuman, menempati posisi peingkatan tertinggi, hal dikarenakan penekanann pada harga pokok produksi yang disertai dengan peningkatan harga jual. Sebaliknya bagi sektor batik malangan, yang mana menempati posisi terendah dalam peningkatan laba bersihnya, di karenakan adanya tingginya biaya produksi, terutama kenaikan bahan baku, upah tenaga kerja serta adanya produk sejenis yang diproduksi secara masal (barang dari china).

Perubahan pada kemampuan bayar (repayment capacyti), batik Malangan $180 \%$, konveksi $134 \%$, peternakan $102 \%$ dan makanan minuman $100 \%$. Kenaikan kamampuan bayar tertinggi pada sektor usaha batik Malangan dikarenakan dipengaruhi secara nominal omzet penjualan yang tinggi dengan didertai oleh ketentuan perhitungan repayment sebesar $80 \%$ oleh pihak lembaga ke-uangan. Sebaliknya peternakan memiliki prosen-tase yang paling rendah yaitu sebesar $102 \%$ per tiga bulan atau hanya $34 \%$ per bulan, kondisi ini dikarenakan sektor usaha petyernakan memiliki resiko tertinggi di bandingkan dengan sektor usaha yang lainnya. Sehingga lembaga keuangan hanya memperhitungkan kemampuan bayar sebesar $60 \%$ dari laba yang diperolehnya.

Dari kenyataan diatas, dapat meberikan gambaran bahwa, bantuan tambahan modal oleh lembaga keuangan bagi usaha mikro masih diperlukan untuk pengembangan usaha. Faktor lain yang perlu dipertimbangkan oleh usaha mikro adalah

Tabel 5: Rakaputulasi Dampak Terukur Lending Model

\begin{tabular}{|l|l|l|l|l|l|l|}
\hline \multicolumn{1}{|c|}{ Kelompok } & \multicolumn{2}{c|}{ Laba Bersih } & \% & \multicolumn{2}{c|}{ Kemampuan Bayar } & $\%$ \\
\hline & \multicolumn{1}{|c|}{ Sebelum } & \multicolumn{1}{c|}{ Sesudah } & & Sebelum & \multicolumn{1}{c|}{ Sesudah } & \\
\hline KONVEKSI & 4.000 .000 & 7.800 .00 & 48,7 & 3.600 .000 & $7.020 .000 ;$ & 95 \\
\hline MAMIN & 3.087 .500 & 8.923 .000 & 65,4 & $3.708 .750 ;$ & 8.030 .700 & 100 \\
\hline${ }^{*}$ PETERNAKAN & 17.500 .000 & 35.500 .000 & 50,7 & 10.500 .000 & 21.300 .000 & 102 \\
\hline $\begin{array}{l}\text { BATIK } \\
\text { MALANGAN }\end{array}$ & 3.750 .000 & 7.000 .000 & 46,4 & 2.000 .000 & 5.600 .000 & 180 \\
\hline
\end{tabular}

Dibayar setiap 3 bulan (saat panen) 
merencanakan efisiensi biaya, karena biaya produksi dari ke empat sektor usaha mikro tersebut masih diatas 60\%. Hal ini berakibat mengurangi laba kotor yang selanjunya akan berdampak pada penurunan laba bersihnya, padahal laba bersih tersbut dia pakai oleh lembaga keuangan sebagai tolok ukur kemampuan bayarnya.

\section{KESIMPULAN}

Keputusan fasilitasi kredit model tanggungrenteng, berdampak terhadap laba perusahaan dan kemampuan bayar. Hal ini berarti dengan tanbah-an modal yang diperoleh dari pinjaman lunak membuat perusahaan beroperasi lebih efisien. Salah satu permalahan utama yang dihadapi oleh usaha mikro pemula dalam memperoleh pinjaman yang lebih besar adalah keterbatasan agunan. Pihak lem-baga keuangan (perbankan) dalam memberikan pinjaman kepada usaha mikro sektor pemula masih setengah hati, karena bisnis usaha mikro dipandang memiliki resiko yang tinggi, sehingga bungan yang di bebankan kepada debitur mikro masih tinggi yaitu diatas 1,5 flat. Sektor usaha makanan minuman, menempati posisi peingkatan laba tertinggi, hal dikarenakan penekanann pada harga pokok produksi yang disertai dengan peningkatan harga jual. Sebaliknya bagi sektor batik malangan, yang mana menempati posisi terendah dalam peningkatan laba bersihnya, di karenakan adanya tingginya biaya produksi, terutama kenaikan bahan baku, upah tenaga kerja serta adanya produk sejenis yang diproduksi secara masal (barang dari china).

\section{SARAN}

Penting bagi usaha mikro, untuk memperoleh pendampingan dari pihak lembaga keuangan maupun lembaga lain khususnya yang terkait dengan tata kelola keuangan. Kelancaran angsuran merupakan kepercayaan yang harus dijaga oleh usaha mikro, maka system angsuran yang semula dilakukan setiap bulan sekali, diperpendek menjadi satu minggu sekali dengan menyediakan tabungan kotak. Kecepatan layanan dari lembaga keuangan (perbankan) perlu di tingkatkan, mengingat fasilitas yang di perlukan oleh pelaku usaha sektor mikro sebagian besar adlah untuk keperluan modal kerja, sehingga kecepatan layanan sangat diperlukan oleh pelaku usaha, sehingga pelaku usaha tidak lagi tergatung dari layanan pelepas uang (rentenir).

\section{DAFTAR PUSTAKA}

Anderson, R. C., \& Reeb, D. M. (2003). FoundingDfamily ownership and firm performance: evidence from the S\&P 500. The journal of finance, 58(3), 1301-1327.

Gardner, Mills ad Cooperman (2005), Managing Financial Institutions, 5th Edition. McGraw-Hill Higher Education

Demirguc-Kunt, Beck and Martinez (2007)and Patrick Honohan. (2008). Finance for All? Policies and Pitfalls in Expanding Access. Washington, DC: The World Bank.

Dewi anggraeni, Syahir hakim, 2013, Peranan Kredit Usaha Rakyat (KUR) Bagi Pengembangan UMKM di Kota Medan, Jurnal Keuangan \& Perbankan, 10

Harash, Emad, Fatima Jasem Alsaad, and Essia Ries Ahmed. (2013) Moderating Effect of Market prac-tices on the Government policy Performance Re-lationship in Iraq SMEs. 4th Global Conference for Academic Research on. Economics, Business and Management. (GCAREBM) 29-30- 2013 Kuala Lumpur, Malaysia

Harash, E., Al-Tamimi, K., \& Al-Timimi, S. (2014). The Relationship Between Government Policy and Fi-nancial Performance: A Study on the SMEs in Iraq. journal China-USA Business Review, Vol. 13, No. 4.

Ittner, C. D., \& Larcker, D. F. (2003). Coming up short on nonfinancial performance measurement. Harvard business review, 81(11), 88-95. 
Juhl, H. J., Kristensen, K., \& 0stergaard, P. (2002). Customer satisfaction in European food retailing. Jour-nal of Retailing and Consumer Services, 9(6), 327-334

Kaplan ad Norton (1992) The Balanced Scorecard: Measures that Drive Performance Harvad, Business School, page 9

Kraja, Y., \& Osmani, E. (2013). Competitive Advantage and ITS Impact in Small and Medium Enterprises (SMEs) (CASE OF ALBANIA). European Scien-tific Journal, 9(16).

Olowe F.T and Moradeyo O.A, Babalola O.A,2013. Empirical Study of the Impact of Microfinance Bank on Small and Medium Growth in Nigeria, International Juournal Academic Research in economic and management sciences, Vol 2.No 6

Ojelabi, Rasheed. O, Jooda Taiwo. D, Adeniran, J.O (2015), Influence of Microfinance Bank on Small and Me-dium Scale Enterprises Growth in Osun State, Negeria

Meyanathan, S.D. \& Munter, R. (1994), "Industrial Struc-tures and the Development of Small and Medium Enterprise Linkages: An Overview", in Meyanathan, S.D. (ed.), op. cit.: 1-22

Pandey, I.M. (1997), Financial Management, 7th Edition, Vika publishing House PVT ltd.

Petersen, M. A., \& Schoeman, I. (2008, July). Modeling of Banking Profit via Return-on-Assets and Return-on • Equity. In Proceedings of the World Congress on Engineering (Vol. 2, pp. 1-6).
Rachmawati \& Hotniar, 2007, Analisis Pengaruh Kredit,Aset dan Jumlah Pegawai Terhadap Pendapatan Usaha Kecil Menengah (UKM) Penerima Kredit Bank Perkreditan Rakyat, Universitas Gunadarma.

Sabanci Ozer, H. (2012). The Role of Family Control on Financial Performance of Family Business in Gebze. International Review of Management and Marketing, 2(2), 75-82.

Sacristan-Navarro, M., Gomez-Anson, S., \& CabezaGarcia, L. (2011). Family ownership and control, the presence of other large shareholders, and firm performance: Further evidence. Family Business Review, 24(1), 71-93.

Selvarajan, T. T., Ramamoorthy, N., Flood, P. C., Guthrie, J. P., MacCurtain, S., \& Liu, W. (2007). The role of human capital philosophy in promoting firm innovativeness and performance: Test of a causal model. The International Journal of Human Resource Management, 18(8), 1456-1470.

Tambunan, T. (2005). Promoting small and medium enterprises with a clustering approach: A policy ex-perience from Indonesia. Journal of Small Busi-ness Management, 43(2), 138-154.

Thrikawala, S. S. (2011). Impact of strategic networks for the success of SMEs in Sri Lanka. World, 1(2), 108-119.

Watson, J. (2007). Modeling the relationship between networking and firm performance. Journal of Busi-ness Venturing, 22(6), 852-874. 
